\title{
Simultaneous supplementation with iron and folic acid can affect Slc11a2 and Slc46a1 transcription and metabolite concentrations in rats
}

\author{
A. Radziejewska ${ }^{1}$, J. Suliburska ${ }^{1}$, P. Kołodziejski ${ }^{2}$ and A. Chmurzynska ${ }^{1 *}$ \\ ${ }^{1}$ Institute of Human Nutrition and Dietetics, Poznań University of Life Sciences, 60-624 Poznañ, Poland \\ ${ }^{2}$ Department of Animal Physiology and Biochemistry, Poznań University of Life Sciences, 60-637 Poznañ, Poland \\ (Submitted 8 March 2019 - Final revision received 30 September 2019 - Accepted 15 October 2019)
}

\begin{abstract}
The present study aimed at analysing how dietary folic acid (FA) and Fe deficiency, followed by supplementation with these nutrients, affects the expression of folate and Fe transporters in the duodenum, as well as FA and Fe status. After a deficiency period, Wistar rats were randomised to a group fed with a diet deficient in FA and supplemented with Fe (DFE), a diet deficient in Fe and supplemented with FA, a diet supplemented with Fe and FA (FEFOL), a diet deficient in Fe and FA (D) or a control diet (C). Tissue collection was performed after 2, 10 or $21 \mathrm{~d}$ of these diets. Group D had higher Slc11a2 mRNA levels than the DFE group at every time point and there were differences in mRNA levels of Slc46a1 between the DFE and the FEFOL groups at the third time point, but we observed no differences in protein levels between the groups. The DFE and D groups not only had lower serum folate concentrations at every time point but also had the highest homocysteine concentrations. Total Fe binding capacity concentrations were the lowest in the DFE group at the first time point and in the DFE and the FEFOL groups at the final time point. Simultaneous supplementation with FA and Fe resulted in significantly higher $\mathrm{Hb}$ concentrations than did supplementation with these nutrients alone. Our findings indicate that dietary FA and Fe deficiency, and subsequent supplementation with these nutrients, affects transcription but not the protein levels of FA and Fe transporters in the duodenum.
\end{abstract}

Key words: Transporters: Folic acid: Iron: Absorption: Supplementation

Proper folic acid (FA) and Fe status is crucial to young women's health and is particularly important during pregnancy because of the development of the placenta and fetus, the increased volume of blood and the muscles of the uterus ${ }^{(1)}$. For this reason, many commercially available supplements contain Fe and FA.

Folate, also known as vitamin $\mathrm{B}_{9}$, is involved in many metabolic reactions and participates in purine and pyrimidine synthesis and one-carbon metabolism ${ }^{(2)}$. Insufficient intake of this nutrient can affect cellular function and lead to metabolic disturbances, such as increased homocysteine (Hcy) concentration ${ }^{(3)}$. Folate deficit impairs DNA synthesis and cell differentiation and thus alters erythropoiesis. Moreover, decreased folate status contributes to erythroblast apoptosis and induces anaemia ${ }^{(4)}$. Increased Hcy concentrations have been linked with embryonic development alterations, but the data on relationships between Hcy and increased incidences of spontaneous abortions are conflicting ${ }^{(5,6)}$. It has also been shown that FA supplementation before and during pregnancy decreases the risk of neural tube defects $^{(7,8)}$. For this reason, many countries recommend supplementation of this nutrient among young women ${ }^{(9)}$ and fortification is mandatory in the USA, Canada and a number of European countries $^{(10)}$.

Fe deficiency caused by a negative Fe balance leads to impaired red blood production and Fe-deficiency anaemia. Fe-deficiency anaemia is one of the most common nutritional deficiencies in the world ${ }^{(11)}$. The WHO reports that, on average, $56 \%$ of pregnant women suffer from anaemia and at least half of this is Fe-deficiency anaemia ${ }^{(12)}$. The adequate intake of food or of supplements containing $\mathrm{Fe}$ is thus essential ${ }^{(13)}$. The prenatal supplementation with $\mathrm{Fe}$ is associated with improved birth weight $^{(14)}$, but Fe-overload is toxic ${ }^{(15)}$.

The status of both Fe and FA primarily depends on dietary intake, absorption in the intestine, transport and excretion. FA is mainly absorbed in the duodenum ${ }^{(16)}$ and, as a negatively charged molecule, it requires a specific membrane transporter to transfer it in and outside of the cell ${ }^{(16)}$. FA absorption is mainly

Abbreviations: C, control diet; D, diet deficient in Fe and folic acid; DFE, diet deficient in folic acid and supplemented with Fe; DFOL, diet deficient in Fe and supplemented with folic acid; FA, folic acid; FEFOL, diet supplemented with Fe and folic acid; Hcy, homocysteine; Pcft, proton-coupled folate transporter; TIBC, total Fe binding capacity.

* Corresponding author: A. Chmurzynska, fax +48 6184873 32, email agata.chmurzynska@up.poznan.pl 
supported in mammals by proton-coupled folate transporter (Pcft), which is encoded by the $S l c 46 a 1$ gene. Pcft requires an acidic environment for optimal functioning and has high affinity for $\mathrm{FA}^{(17)}$. Pcft has been established as a folate transporter but was originally identified as haem carrier protein 1 and characterised as a mammalian haem transporter ${ }^{(18)}$. It has subsequently been shown that this transporter has a lower affinity to haem than to folate, but there is competitive uptake of folate and haem by it. For this reason, a high intake of haem may lead to impaired absorption of folate and high uptake of folate conversely leads to decreased absorption of haem $\mathrm{Fe}^{(19)}$. However, Fe absorption also depends on nonhaem Fe uptake via other transporters ${ }^{(20)}$. Fe absorption from the proximal small bowel is a critical step in the maintenance of Fe homeostasis ${ }^{(21)}$. Fe transport from the lumen of the gut into duodenal enterocytes is mediated by the divalent metal transporter 1 , which is encoded by the Slc11a2 gene. Divalent metal transporter 1 functions as a $\mathrm{Fe}(\mathrm{II}) /$ proton symporter. Fe(III) is also transported by divalent metal transporter 1 after reduction to $\mathrm{Fe}(\mathrm{II})$ by duodenal cytochrome B (DcytB) ${ }^{(22)}$. Moreover, dysfunction of SLC11A2 leads to impaired $\mathrm{Fe}$ absorption and dramatically increases the expression of its transcript in rodents ${ }^{(23)}$.

Fe deficiency results in elevated Fe requirements. It has been shown that expression of the Slc11a2 gene is tissue-specific and that its level of expression is related to Fe status. A compensation mechanism leads to increased Slc11a2 transcription and thus an increased abundance of transporters, which thus leads to accelerated absorption of $\mathrm{Fe}^{(23,24)}$. A similar observation has been noticed in rodent and in vitro models of folate deficiency, and folate deficiency increases expression levels of folate transporters ${ }^{(25-27)}$. However, there is no data on the effect of simultaneously supplementing Fe and FA after a deficiency of these nutrients on their transporter function. Moreover, there is limited information about the time response to supplementation following a deficiency of these nutrients ${ }^{(27)}$

The aim of the present study was thus to determine how FA and Fe deficiency, and the subsequent supplementation of the rat diet with these nutrients, affects Slc11a2 and Slc46a1 gene expression and metabolic biomarkers of FA and Fe status.

\section{Methods}

\section{Animals and diet}

The experimental procedures were conducted in compliance with the international principles for laboratory animals and protocols approved by the Bioethical Commission for Animal Care and Use in Poznań, Poland (approval no. 59/2016). One hundred and fifty female Wistar rats of 8 weeks of age were purchased from AnimaLab (Germany). The animals were housed in cages with a $12 \mathrm{~h}$ light $-12 \mathrm{~h}$ dark cycle in an environmentally controlled room at $20-22^{\circ} \mathrm{C}$. Following an acclimatisation period, the animals were randomly assigned to either a group fed a diet deficient in Fe and FA (D, $n$ 120) or to a group fed a control diet (C, $n$ 30) for $28 \mathrm{~d}$. The control diet was AIN$93 \mathrm{M}$. After this period, animals in the D group were randomised to a group fed with a diet deficient in FA and supplemented with $\mathrm{Fe}$ (DFE), a group fed with a diet deficient in Fe and
Table 1. Composition of diets

\begin{tabular}{|c|c|}
\hline Experimental group & Diet \\
\hline C & Standard diet (AIN-93M) \\
\hline $\mathrm{D}$ & Deficient diet \\
\hline DFE & $\mathrm{D}+150 \mathrm{mg} \mathrm{Fe} / \mathrm{kg}$ \\
\hline DFOL & $\mathrm{D}+6 \mathrm{mg} \mathrm{FA} / \mathrm{kg}$ \\
\hline FEFOL & $\mathrm{D}+150 \mathrm{mg} \mathrm{Fe} / \mathrm{kg}+6 \mathrm{mg} \mathrm{FA} / \mathrm{kg}$ \\
\hline \multicolumn{2}{|c|}{$\begin{array}{l}\text { C, control diet; AIN, American Institute of Nutrition; D, diet } \\
\text { deficient in Fe and folic acid; DFE, diet deficient in folic acid } \\
\text { and supplemented with Fe; DFOL, diet deficient in Fe and } \\
\text { supplemented with folic acid; FA, folic acid; FEFOL, diet } \\
\text { supplemented with Fe and folic acid. }\end{array}$} \\
\hline
\end{tabular}

Table 2. Composition of vitamin and mineral mixes in the experimental diets* $^{*}$

\begin{tabular}{lccccc}
\hline & DFE & DFOL & FEFOL & D & C \\
\hline Vitamin A (U/kg) & 4000 & 4000 & 4000 & 4000 & 4000 \\
Vitamin D $(\mathrm{U} / \mathrm{kg})$ & 1000 & 1000 & 1000 & 1000 & 1000 \\
Vitamin E (U/kg) & 80 & 80 & 80 & 80 & 80 \\
Vitamin K (U/kg) & 0.751 & 0.751 & 0.751 & 0.751 & 0.751 \\
Thiamin (mg) & 5 & 5 & 5 & 5 & 5 \\
Riboflavin (mg) & 6 & 6 & 6 & 6 & 6 \\
Niacin (mg) & 30 & 30 & 30 & 30 & 30 \\
Pantothenic acid (mg) & 15 & 15 & 15 & 15 & 15 \\
Folic acid (mg) & 0 & 6 & 6 & 0 & 2 \\
Pyridoxine (mg) & 6 & 6 & 6 & 6 & 6 \\
D-Biotin (mg) & 0.200 & 0.200 & 0.200 & 0.200 & 0.200 \\
Vitamin B 12 (mg) & 0.033 & 0.033 & 0.033 & 0.033 & 0.033 \\
Choline chloride (mg) & 8 & 8 & 8 & 8 & 8 \\
Ca (mg) & 5000 & 5000 & 5000 & 5000 & 5000 \\
P (mg) & 3000 & 3000 & 3000 & 3000 & 3000 \\
K (mg) & 4000 & 4000 & 4000 & 4000 & 4000 \\
Mg (mg) & 500 & 500 & 500 & 500 & 500 \\
Na (mg) & 1000 & 1000 & 1000 & 1000 & 1000 \\
Cl (mg) & 1565 & 1565 & 1565 & 1565 & 1565 \\
F (mg) & 1.64 & 1.64 & 1.64 & 1.64 & 1.64 \\
Fe (mg) & 150 & 0 & 150 & 0 & 50 \\
Zn (mg) & 35 & 35 & 35 & 35 & 35 \\
Mn (mg) & 9.92 & 9.92 & 9.92 & 9.92 & 9.92 \\
Cu (mg) & 7.87 & 7.87 & 7.87 & 7.87 & 7.87 \\
I (mg) & 0.28 & 0.28 & 0.28 & 0.28 & 0.28 \\
Cr (mg) & 1 & 1 & 1 & 1 & 1 \\
Se (mg) & 0.20 & 0.20 & 0.20 & 0.20 & 0.20 \\
\hline
\end{tabular}

$\mathrm{DFE}$, diet deficient in folic acid and supplemented with $\mathrm{Fe}$; DFOL, diet deficient in Fe and supplemented with folic acid; FEFOL, diet supplemented with $\mathrm{Fe}$ and folic acid; $\mathrm{D}$, diet deficient in Fe and folic acid; C, control diet.

${ }^{*}$ All values are expressed per kg of diet.

supplemented with FA (DFOL), a group fed with a diet supplemented with Fe and FA (FEFOL), a diet deficient in Fe and FA (D) or a group fed the control diet (C) until the end of the experiment. Detailed information on dietary composition is presented in Tables 1 and 2. Rats were given food and water ad libitum. Ten rats from each group were killed after 2, 10 and $21 \mathrm{~d}$ of the modified diet. The full study design is shown in Fig. 1. During the experiment, food intake was monitored daily and body weight was measured using an electronic scale.

\section{Tissue and blood sampling}

The animals were fasted overnight for up to $12 \mathrm{~h}$ and were killed by decapitation. Duodenum samples were frozen immediately in liquid $\mathrm{N}_{2}$ and stored at $-80^{\circ} \mathrm{C}$ for further analysis. Blood 


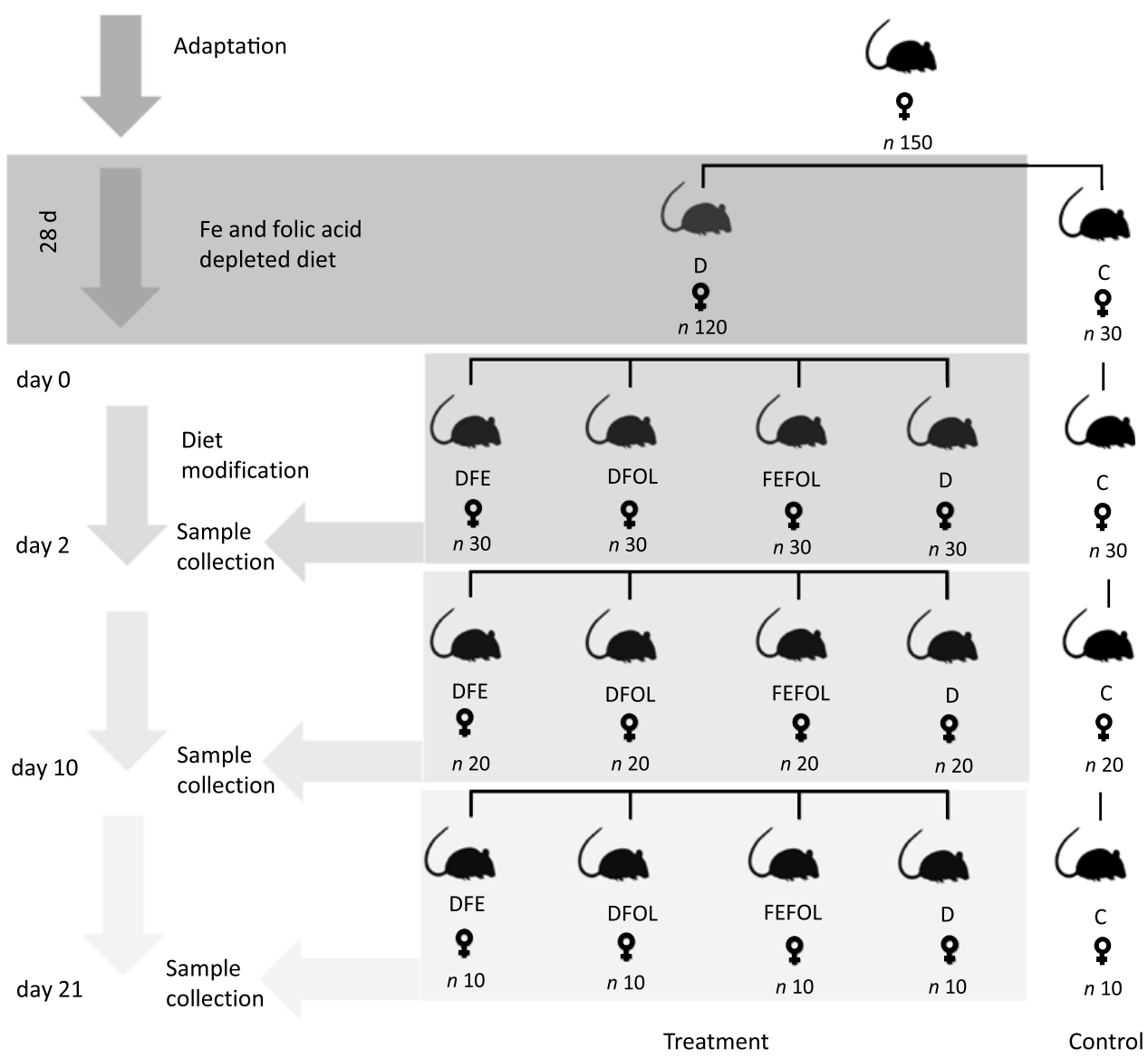

Fig. 1. Study design. D, diet deficient in iron and folic acid; C, control diet; DFE, diet deficient in folic acid and supplemented with iron; DFOL, diet deficient in iron and supplemented with folic acid; FEFOL, diet supplemented with iron and folic acid.

was collected into standard vials and allowed to clot at room temperature for $1 \mathrm{~h}$. The sample was then centrifuged at $14000 \mathrm{rpm}$ for $6 \mathrm{~min}$, and the serum was collected and stored at $-80^{\circ} \mathrm{C}$. For the plasma samples, the blood was collected to a microtainer and centrifuged at $14000 \mathrm{rpm}$ for $6 \mathrm{~min}$ at $4^{\circ} \mathrm{C}$ and then collected and stored at $-80^{\circ} \mathrm{C}$.

\section{Real-time $P C R$}

The relative transcript levels were measured for genes encoding folate and Fe transporters - namely, Slc46a1 and Slc11a2. All details of primer and probe sequences are shown in Table 3. Total RNA was extracted from the liver and duodenum using a commercial kit (High Pure RNA Isolation Kit, Roche) and following the manufacturer's protocol. The quality and quantity of RNA were assessed using a microvolume spectrophotometer (DS-11, DeNovix). The cDNA synthesis used $1 \mu \mathrm{g}$ of RNA with a Transcriptor First Strand Synthesis Kit (Roche). Real-time reactions were performed in duplicate for all the rat samples using a Light Cycler 480 Instrument (Roche) with Universal Probe Library probes and LightCycler 480 Probes Master (Roche). The assays were intron-spanning. The real-time PCR cycle consisted of denaturation at $95^{\circ} \mathrm{C}$ for $10 \mathrm{~min}$, followed by forty-five cycles of denaturation at $95^{\circ} \mathrm{C}$ for $10 \mathrm{~s}$, annealing at $56^{\circ} \mathrm{C}$ for $30 \mathrm{~s}$, and elongation at $72^{\circ} \mathrm{C}$ for $1 \mathrm{~s}$. To normalise the data, we employed arithmetic means of transcription levels of two reference genes: 18 s subunit ribosomal $R N A$ and Actin $\beta$. Relative quantification of the mRNA level was performed based on the second derivative maximum method (Roche).

\section{Protein isolation}

Proteins were isolated from $200 \mathrm{mg}$ of tissue. Mechanical homogenisation was conducted in ice-cold radioimmunoprecipitation assay (RIPA) buffer (containing $50 \mathrm{mmol}$ Tris-HCl, $\mathrm{pH} 8.0$ with $150 \mathrm{~mm} \mathrm{NaCl}, 1.0 \% \mathrm{NP}-40,0.5 \%$ sodium deoxycholate, $0.1 \%$ SDS, $10 \mathrm{~mm} \mathrm{NaF}$ and $1 \mathrm{~mm} \mathrm{Na}_{3} \mathrm{VO}_{4}$ ) supplemented with a cocktail of proteases inhibitors. Samples were centrifuged at $12000 \mathbf{g}$. Protein concentration was determined using a bicinchoninic acid (BCA) kit (Thermo Scientific).

\section{Western Blot}

Samples containing $20 \mu \mathrm{g}$ of proteins were mixed in a 1:3 ratio $(\mathrm{w} / \mathrm{v})$ with $4 \times$ Laemmli buffer (BioRad), supplemented with $\beta$-mercaptoethanol and denatured for $5 \mathrm{~min}$ at $95^{\circ} \mathrm{C}$. Electrophoresis was performed in $4 \%$ acrylamide stacking gel and $12 \%$ resolving gel for approximately $1.5 \mathrm{~h}$ at $125 \mathrm{~V}$. The resolved proteins were transferred into a nitrocellulose membrane in a semidry transfer procedure with a Towbin buffer at 0.3 A for $10 \mathrm{~min}$ Trans-Blot Turbo Blotting System (BioRad). 
Table 3. Real-time PCR primers and amplicon lengths of the studied genes

\begin{tabular}{|c|c|c|c|}
\hline Gene & Primer sequences & Probe & $\begin{array}{l}\text { Amplicon } \\
\text { length }\end{array}$ \\
\hline Dmt1 & $\begin{array}{l}\text { L: } 5^{\prime} \text { gcaggaagtcattggctcag } \\
\text { R: } 5^{\prime} \text { gactccaccatacaggggaac }\end{array}$ & $\begin{array}{l}\# 112 \text { Roche (cat. } \\
\text { no. } 04693469001 \text { ) }\end{array}$ & $73 \mathrm{nt}$ \\
\hline Pcft & $\begin{array}{l}\text { L: } 5^{\prime} \text { ggagctggectcctctttat } \\
\text { R: } 5^{\prime} \text { ccactgcttctcatggcttc }\end{array}$ & $\begin{array}{l}\# 120 \text { Roche (cat. } \\
\text { no. } 04693540001 \text { ) }\end{array}$ & $123 \mathrm{nt}$ \\
\hline Actb & $\begin{array}{l}\text { L: } 5^{\prime} \text { ctaaggccaaccgtgaaaag } \\
\text { R: } 5^{\prime} \text { tacatggctggggtgttga }\end{array}$ & $\begin{array}{l}\# 115 \text { Roche (cat. } \\
\text { no. } 04693493001 \text { ) }\end{array}$ & $64 \mathrm{nt}$ \\
\hline $\begin{array}{l}18 s \\
r R N A\end{array}$ & $\begin{array}{l}\text { L: } 5^{\prime} \text { ggtgcatggccgttctta } \\
\text { R: } 5^{\prime} \text { aactagttagcatgccgagagtc }\end{array}$ & $\begin{array}{l}\text { \#22 Roche (cat. } \\
\text { no. 04686969001) }\end{array}$ & $83 \mathrm{nt}$ \\
\hline
\end{tabular}

Dmt1, divalent metal-ion transporter 1; nt, nucleotides; Pcft, proton-coupled folate transporter; Actb, actin $\beta ; 18 s$ rRNA, 18S ribosomal RNA.

Protein band visualisations were performed with an 1 min incubation in Ponceau S solution. The membrane was then blocked by incubating with $3 \%$ bovine serum albumin (BSA) in TBST solution for $1 \mathrm{~h}$. The membrane was incubated with a primary antibody (SLC46A1 Antibody, Aviva Systems Biology; SLC11A2 Antibody, Santa Cruz Biotechnology) diluted to 1:1000 in TBST supplemented with $1 \%$ of BSA at $4^{\circ} \mathrm{C}$ overnight. Specificity of both antibodies has been verified prior to the study. The membrane was then washed three times for $10 \mathrm{~min}$ and incubated with secondary antibody diluted to $1: 5000$ for $1 \mathrm{~h}$. The signal was visualised using an ECL substrate (Thermo Scientific) on a ChemiDoc Touch Imaging System (BioRad).

\section{Biochemical parameters}

Fe concentrations were determined in serum using a commercial kit (Thermo Scientific). Unsaturated Fe binding capacity concentrations were assayed in serum using the photometric method with ferene (DiaSys) with a Konelab 20i biochemical analyser (Thermo Electron). Total Fe binding capacity (TIBC) was calculated by summing the unsaturated Fe binding capacity and Fe concentrations. Folate concentrations were determined using the electrochemiluminescence method with a Cobas 6000 (Roche Diagnostics) and reagent Folate III test (Roche Diagnostics GmbH). Plasma Hcy levels were determined using enzyme-cycling Hcy assay with commercial kits (Diazyme Homocysteine Assay, Diazyme Laboratories) and a fully automated Konelab 20i Analyser (Thermo Electron). Whole-blood morphological analysis was performed by a commercial laboratory with the use of SYSMEX XT-4000 (Synevo).

\section{Statistical analysis}

The results are presented as mean values and standard deviations. Differences between groups were assessed using one-way ANOVA followed by a post hoc Scheffé's test. Transcripts and protein levels were compared by Kruskal-Wallis analysis. $P<0.05$ was taken to be statistically significant.

Sample size was calculated using power analysis. Significance level was $0 \cdot 05$, assumed a two-sided test of the hypothesis and $0 \cdot 8$ was considered as adequate. Taking the $\mathrm{Hb}$ standard deviation as
Table 4. Body weight of each animal group ( $n 10$ per group) (Mean values and standard deviations)

\begin{tabular}{|c|c|c|c|c|c|c|c|}
\hline \multirow[b]{2}{*}{ Group } & \multicolumn{2}{|c|}{$\begin{array}{l}\text { Body mass }(\mathrm{g}) \\
\text { at first time } \\
\text { point }\end{array}$} & \multicolumn{2}{|c|}{$\begin{array}{c}\text { Body mass (g) } \\
\text { at second time } \\
\text { point }\end{array}$} & \multicolumn{2}{|c|}{$\begin{array}{l}\text { Body mass }(\mathrm{g}) \\
\text { at third time } \\
\text { point }\end{array}$} & \multirow[b]{2}{*}{$P^{*}$} \\
\hline & Mean & SD & Mean & $\mathrm{SD}$ & Mean & SD & \\
\hline $\mathrm{C}$ & 254.99 & 14.48 & 263.45 & 14.97 & 279.08 & $27 \cdot 91$ & NS \\
\hline D & 259.89 & 19.36 & 269.60 & $16 \cdot 16$ & $281 \cdot 16$ & 17.43 & NS \\
\hline DFE & 248.51 & 16.89 & 258.39 & 16.64 & 279.29 & 23.94 & NS \\
\hline DFOL & $251 \cdot 75$ & 19.79 & $265 \cdot 33$ & 12.63 & 276.90 & 25.89 & NS \\
\hline FEFOL & 254.90 & 15.71 & $276 \cdot 41$ & 22.79 & 278.41 & 12.78 & NS \\
\hline
\end{tabular}

C, control diet; D, diet deficient in Fe and folic acid; DFE, diet deficient in folic acid and supplemented with Fe; DFOL, diet deficient in Fe and supplemented with folic acid; FEFOL, diet supplemented with Fe and folic acid.

${ }^{*} P$ values show the significance levels for the differences between dietary groups within sample collection days.

$6.2 \mathrm{~g} / \mathrm{l}$, ten animals gave as $87 \%$ power to detect a difference between groups. Calculations were performed with the use of Statistica software (StatSoft).

\section{Results}

Intake of the experimental diets did not differ between the groups, nor did we observe body mass differences between the groups. Mean body weights are presented in Table 4 .

We attempted to determine how the dietary regimen affected the expression of the genes that code for transporters of FA (SLC46A1) and Fe (SLC11A2) in the duodenum. We saw lower transcript levels of Slc11a2 in the DFE than in the D animals at all three points in time $(P<0 \cdot 01$; Fig. 2$)$. However, there were no differences between the DFE and the $\mathrm{C}$ group (Fig. 2). At the second and third time points, significantly lower expression of Slc11a2 in the FEFOL group than in the D group was observed $(P<0.01$ and $P<0.001$, respectively). We observed intergroup differences in Slc46a1 gene expression on day 2 of the experiment (Fig. 3), but after $10 \mathrm{~d}$, its expression was higher in the $\mathrm{C}$ group than in the DFOL $(P<0 \cdot 01)$ and D groups $(P<0.001)$ (Fig. 3). After $21 \mathrm{~d}$ on the diets, the DFE group had higher expression of Slc $46 a 1$ than the FEFOL group $(P<0 \cdot 05$; Fig. 3).

We also analysed the protein levels of FA and Fe transporters, but we did not observe any differences in the relative protein levels between the groups at any time point (online Supplementary Figs. S1-S5).

Concentrations of plasma TIBC, unsaturated Fe binding capacity, Fe, folate and Hcy were compared between the groups after 2, 10 and $21 \mathrm{~d}$ of feeding animals with the experimental diets. After $2 \mathrm{~d}$ on the experimental diets, the rats in the DFE groups had lower concentrations of TIBC than in the D group $(P<0.01 ;$ see Table 5$)$. Similar results were observed after $21 \mathrm{~d}(P<0.001)$. However, we did not find any differences in serum Fe concentrations between the groups. Folate concentrations after day 2 were highest in the $\mathrm{C}$ group $(P<0 \cdot 001)$. After the second sample collection day, the FA deficient groups (DFE, D) had significantly lower FA concentrations than the 
(a)

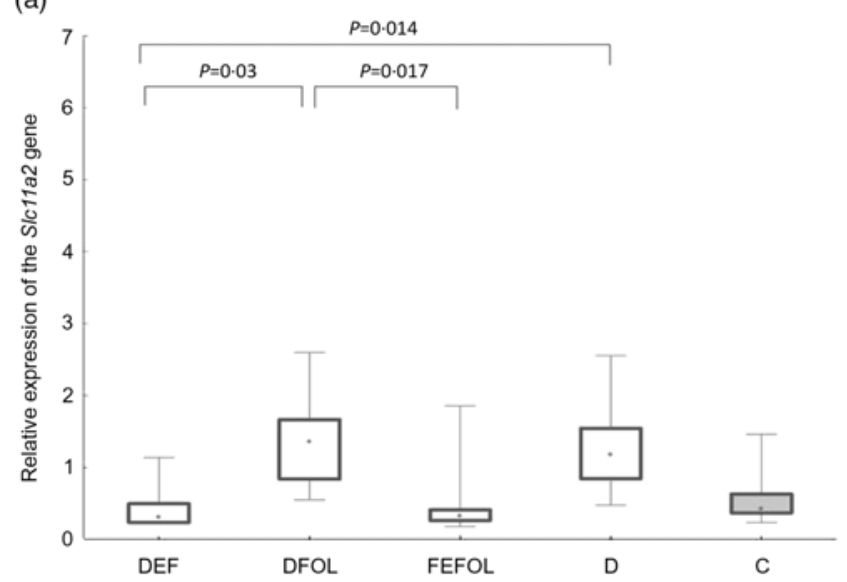

(b)

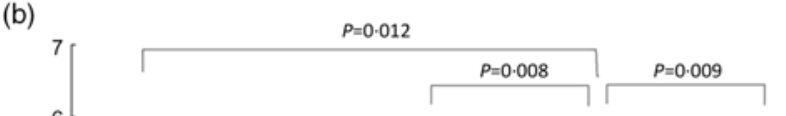

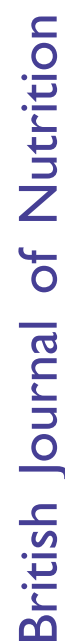

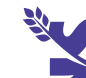

(c)
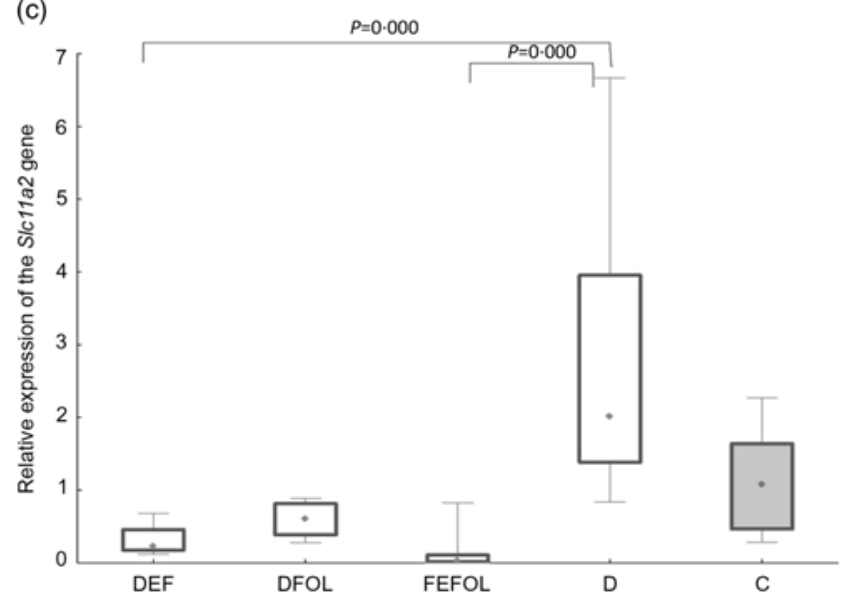

Fig. 2. Relative expression of the S/c11a2 gene in the duodenum at (a) the first ( $n 9-10$ per group), (b) the second ( $n 9-10$ per group) (c) and third time points ( $n$ 4-10 per group). DFE, diet deficient in folic acid and supplemented with iron; DFOL, diet deficient in iron and supplemented with folic acid; FEFOL, diet supplemented with iron and folic acid; D, diet deficient in iron and folic acid; C, control diet. (a) ( $\diamond)$, Median; $(\square), 25-75 \%$; $(\square)$, range within 1.5 interquartile range (IQR). (b) ( $\diamond$ ), Median; ( $\square$ ), 25-75\%; ( () , range within 1.5 IQR. (c) ( $\diamond)$, Median; $(\square)$, 25-75\%; ( $)$, range within 1.5 IQR.

supplemented groups (DFOL, FEFOL) and the $\mathrm{C}$ group $(P<0.001)$. We also examined Hcy plasma concentrations. After 10 and $21 \mathrm{~d}$, we observed that the FA supplemented rats (DFOL and FEFOL), as well as the $\mathrm{C}$ group, had significantly
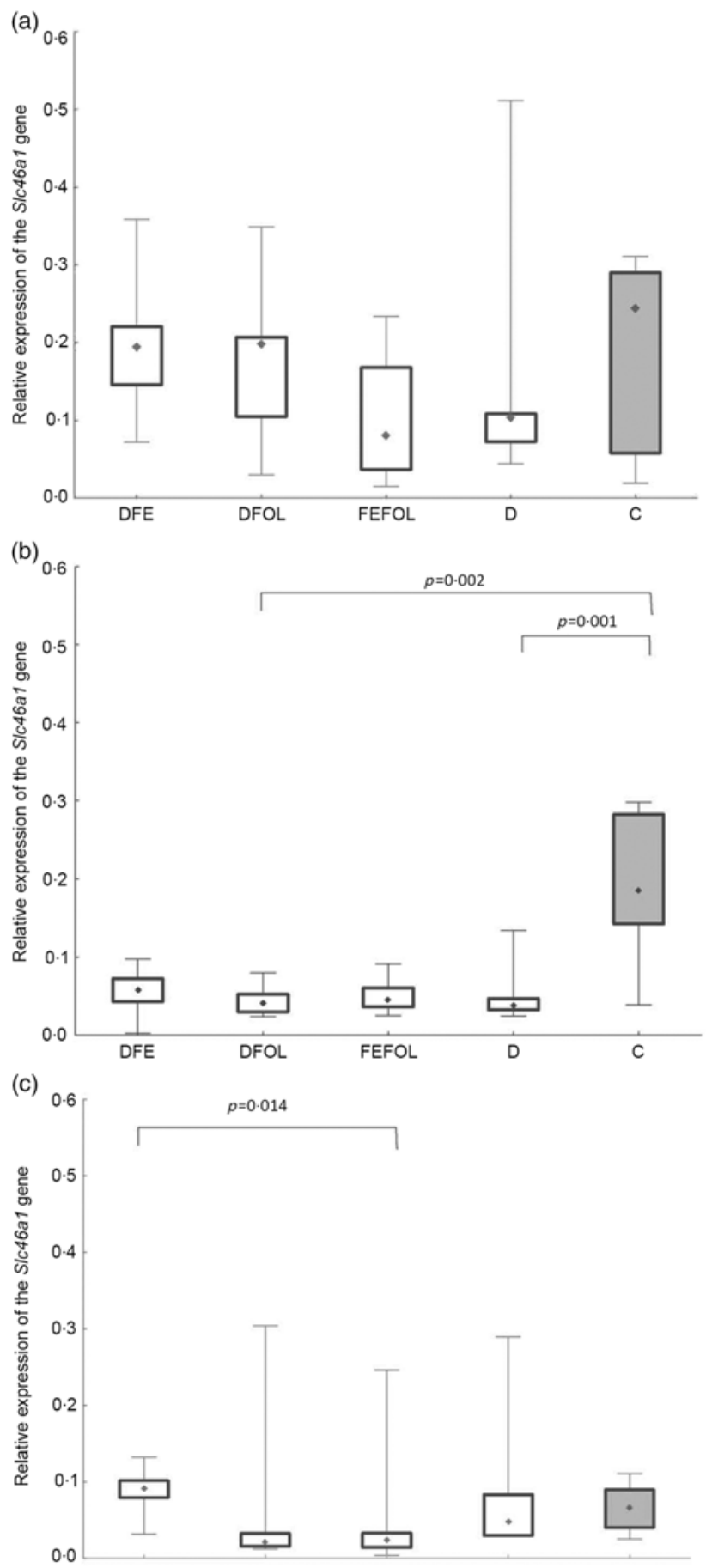

Fig. 3. Relative expression of the Slc46a1 gene in the duodenum at (a) the first ( $n$ 9-10 per group), (b) the second ( $n 7-10$ per group) and (c) the third time points ( $n 6-10$ per group). DFE, diet deficient in folic acid and supplemented with iron; DFOL, diet deficient in iron and supplemented with folic acid; FEFOL, diet supplemented with iron and folic acid; D, diet deficient in iron and folic acid; C, control diet. (a) ( $\diamond$ ), Median; ( $\square$ ), 25-75\%; ( $)$, range within 1.5 interquartile range (IQR). (b) ( $\diamond$ ), Median; ( $\square$ ), 25-75\%; ( $)$, range within 1.5 IQR. (c) ( $\diamond)$, Median; ( $\square$ ), 25-75\%; ( $\square$ ), range within 1.5 IQR.

lower Hcy concentrations than the two FA deficient groups ( $P<0.001$; see Table 5 ). At the third time point, we observed significantly higher $\mathrm{Hb}$ concentrations in the FEFOL and $\mathrm{C}$ groups than in the D group $(P<0 \cdot 01$; see Table 6$)$. Haematocrit was 
Table 5. Concentration of blood metabolites across sample collection days ( $n 9$ (lack of data) or 10 per group)

(Mean values and standard deviations)

\begin{tabular}{|c|c|c|c|c|c|c|c|c|c|c|c|}
\hline & \multicolumn{2}{|c|}{ DFE } & \multicolumn{2}{|c|}{ DFOL } & \multicolumn{2}{|c|}{ FEFOL } & \multicolumn{2}{|c|}{$D$} & \multicolumn{2}{|c|}{$\mathrm{C}$} & \multirow[b]{2}{*}{$P^{\star}$} \\
\hline & Mean & SD & Mean & SD & Mean & SD & Mean & SD & Mean & SD & \\
\hline \multicolumn{12}{|c|}{ First time point (2nd day) } \\
\hline $\mathrm{TIBC}(\mu \mathrm{mol} / \mathrm{l})$ & $98.59^{a}$ & $5 \cdot 41$ & $113 \cdot 56^{b}$ & 11.52 & $107 \cdot 68^{a, b}$ & 14.96 & $120 \cdot 36^{b}$ & $18 \cdot 28$ & $105 \cdot 35^{a, b}$ & 3.04 & $<0.001$ \\
\hline UIBC $(\mu \mathrm{mol} / \mathrm{l})$ & $41 \cdot 17^{a}$ & 13.05 & $73 \cdot 38^{b}$ & 21.88 & $58 \cdot 57^{\mathrm{a}, \mathrm{b}}$ & 23.61 & $77 \cdot 19^{\mathrm{b}}$ & $25 \cdot 30$ & $54 \cdot 74^{\mathrm{a}, \mathrm{b}}$ & $14 \cdot 61$ & $<0.01$ \\
\hline $\mathrm{Fe}(\mu \mathrm{mol} / \mathrm{l})$ & $57 \cdot 42$ & $12 \cdot 88$ & $40 \cdot 18$ & 0.14 & $49 \cdot 12$ & $15 \cdot 76$ & $43 \cdot 17$ & $21 \cdot 17$ & $50 \cdot 61$ & $13 \cdot 14$ & NS \\
\hline Folate (nmol/l) & $27 \cdot 66^{a}$ & $13 \cdot 50$ & $40 \cdot 79^{a, b}$ & $10 \cdot 10$ & $49 \cdot 04^{b}$ & $16 \cdot 53$ & $25 \cdot 71^{\mathrm{a}}$ & $7 \cdot 52$ & $86 \cdot 75^{c}$ & $10 \cdot 44$ & $<0.001$ \\
\hline Hcy $(\mu \mathrm{mol} / \mathrm{l})$ & $19 \cdot 22^{a, b}$ & 5.58 & $9 \cdot 24^{\mathrm{a}}$ & $7 \cdot 01$ & $12 \cdot 49^{a}$ & $4 \cdot 39$ & $26 \cdot 92^{b}$ & $15 \cdot 82$ & $10 \cdot 58^{a}$ & 1.47 & $<0.05$ \\
\hline \multicolumn{12}{|c|}{ Second time point (10th day) } \\
\hline $\mathrm{TIBC}(\mu \mathrm{mol} / \mathrm{l})$ & $104 \cdot 78$ & 13.51 & $110 \cdot 17$ & 5.55 & $106 \cdot 62$ & $7 \cdot 67$ & $113 \cdot 38$ & $17 \cdot 21$ & $103 \cdot 11$ & $8 \cdot 77$ & NS \\
\hline UIBC $(\mu \mathrm{mol} / \mathrm{l})$ & 59.95 & $30 \cdot 11$ & $70 \cdot 91$ & $14 \cdot 68$ & 63.25 & $12 \cdot 31$ & $80 \cdot 25$ & $27 \cdot 57$ & $60 \cdot 18$ & $16 \cdot 34$ & NS \\
\hline $\mathrm{Fe}(\mu \mathrm{mol} / \mathrm{l})$ & $44 \cdot 82$ & $18 \cdot 82$ & $39 \cdot 26$ & $12 \cdot 50$ & $39 \cdot 37$ & $9 \cdot 50$ & $38 \cdot 12$ & $13 \cdot 42$ & 42.97 & $8 \cdot 87$ & NS \\
\hline Folate (nmol/l) & $28.54^{a}$ & $9 \cdot 24$ & $99 \cdot 82^{b}$ & $6 \cdot 70$ & $95 \cdot 45^{\mathrm{b}}$ & 8.56 & $22 \cdot 72^{\mathrm{a}}$ & $5 \cdot 71$ & $92 \cdot 09^{b}$ & 14.95 & $<0.001$ \\
\hline Hcy $(\mu \mathrm{mol} / \mathrm{l})$ & $23 \cdot 80^{b}$ & 8.82 & $9 \cdot 42^{\mathrm{a}}$ & $2 \cdot 13$ & $10 \cdot 48^{a}$ & 2.79 & $27 \cdot 73^{b}$ & $14 \cdot 78$ & $10 \cdot 35^{a}$ & 1.44 & $<0.001$ \\
\hline \multicolumn{12}{|c|}{ Third time point (21st day) } \\
\hline TIBC $(\mu \mathrm{mol} / \mathrm{l})$ & $92 \cdot 00^{\mathrm{a}}$ & $7 \cdot 91$ & $117 \cdot 84^{\mathrm{b}, \mathrm{c}}$ & 13.44 & $94 \cdot 15^{a}$ & 3.54 & $125 \cdot 57^{c}$ & $22 \cdot 83$ & $102 \cdot 28^{a, b}$ & $8 \cdot 23$ & $<0.001$ \\
\hline UIBC $(\mu \mathrm{mol} / \mathrm{l})$ & $53.86^{a}$ & $15 \cdot 87$ & $88 \cdot 27^{b}$ & $21 \cdot 36$ & $53.52^{\mathrm{a}}$ & 11.60 & $86 \cdot 33^{a, b}$ & 34.55 & $55 \cdot 42^{\mathrm{a}}$ & $19 \cdot 05$ & $<0.001$ \\
\hline $\mathrm{Fe}(\mu \mathrm{mol} / \mathrm{l})$ & $38 \cdot 13$ & $11 \cdot 82$ & 29.56 & $10 \cdot 66$ & $40 \cdot 62$ & $10 \cdot 97$ & 39.25 & $13 \cdot 78$ & $46 \cdot 86$ & $15 \cdot 15$ & NS \\
\hline Folate (nmol/l) & $20 \cdot 07^{a}$ & $10 \cdot 85$ & $100 \cdot 59^{b}$ & $6 \cdot 73$ & $102 \cdot 79^{b}$ & 8.97 & $16 \cdot 22^{\mathrm{a}}$ & $7 \cdot 27$ & $95 \cdot 95^{\mathrm{a}, \mathrm{b}}$ & $12 \cdot 55$ & $<0.001$ \\
\hline Hcy $(\mu \mathrm{mol} / \mathrm{l})$ & $28 \cdot 84^{b}$ & $12 \cdot 81$ & $10 \cdot 16^{a}$ & 1.04 & $8 \cdot 29^{a}$ & 1.88 & $41.48^{b}$ & 22.07 & $9.76^{a}$ & 2.87 & $<0.001$ \\
\hline
\end{tabular}

deficient in Fe and folic acid; C, control diet; TIBC, total Fe binding capacity; UIBC, unsaturated Fe binding capacity; Hcy, homocysteine.

a,b Mean values within a row with unlike superscript letters are significantly different $(P<0.05$; Scheffé's test).

* $P$ values show the significance levels for differences between dietary groups within sample collection days.

Table 6. Concentrations of morphological parameters ( $n 9$ (lack of data) or 10 per group)

(Mean values and standard deviations)

\begin{tabular}{|c|c|c|c|c|c|c|c|c|c|c|c|}
\hline & \multicolumn{2}{|c|}{ DFE } & \multicolumn{2}{|c|}{ DFOL } & \multicolumn{2}{|c|}{ FEFOL } & \multicolumn{2}{|c|}{$\mathrm{D}$} & \multicolumn{2}{|c|}{$\mathrm{C}$} & \multirow[b]{2}{*}{$P^{\star}$} \\
\hline & Mean & SD & Mean & SD & Mean & SD & Mean & SD & Mean & SD & \\
\hline \multicolumn{12}{|c|}{ First time point (2nd day) } \\
\hline $\mathrm{Hb}(\mathrm{g} / \mathrm{l})$ & $141 \cdot 75$ & 4.57 & $147 \cdot 50$ & $7 \cdot 78$ & 148.50 & 4.51 & $146 \cdot 25$ & 3.30 & $152 \cdot 00$ & 3.61 & NS \\
\hline $\mathrm{Htc}$ & 0.46 & 0.01 & 0.48 & 0.026 & 0.48 & 0.01 & 0.47 & 0.02 & 0.47 & 0.03 & NS \\
\hline $\operatorname{Mcv}(\mathrm{fl})$ & $60 \cdot 25$ & $2 \cdot 16$ & $58 \cdot 65$ & 1.91 & 59.93 & $2 \cdot 14$ & $59 \cdot 28$ & 0.84 & $62 \cdot 07$ & 0.81 & NS \\
\hline Mch (pg) & $18 \cdot 55$ & 0.48 & $18 \cdot 15$ & 0.49 & $18 \cdot 53$ & 0.63 & $18 \cdot 55$ & 0.35 & $19 \cdot 40$ & 0.27 & NS \\
\hline Mchc $(g / l)$ & $308 \cdot 25$ & $5 \cdot 32$ & 309.50 & 0.71 & $309 \cdot 00$ & 3.56 & $312 \cdot 75$ & $4 \cdot 27$ & 312.67 & $2 \cdot 89$ & NS \\
\hline \multicolumn{12}{|c|}{ Second time point (10th day) } \\
\hline $\mathrm{Hb}(\mathrm{g} / \mathrm{l})$ & $150 \cdot 50$ & $5 \cdot 20$ & $148 \cdot 50$ & $2 \cdot 12$ & $147 \cdot 00$ & $4 \cdot 24$ & $146 \cdot 25$ & 3.30 & $151 \cdot 00$ & 3.46 & NS \\
\hline $\mathrm{Htc}$ & 0.47 & 0.02 & 0.47 & 0.01 & 0.46 & 0.02 & 0.47 & 0.01 & 0.46 & 0.02 & NS \\
\hline $\operatorname{Mcv}(\mathrm{fl})$ & $58.55^{a}$ & 1.05 & $58 \cdot 50^{a}$ & 0.14 & $58 \cdot 40^{\mathrm{a}}$ & 1.53 & $59 \cdot 28^{a, b}$ & 0.84 & $62 \cdot 17^{b}$ & 0.81 & $<0.01$ \\
\hline Mch (pg) & $18 \cdot 60$ & 0.18 & 18.65 & 0.07 & $18 \cdot 75$ & 0.45 & $18 \cdot 55$ & 0.35 & $19 \cdot 37^{b}$ & 0.35 & NS \\
\hline Mchc $(g / l)$ & $317 \cdot 50$ & $3 \cdot 32$ & $319 \cdot 00$ & 0.00 & $321 \cdot 25$ & $5 \cdot 38$ & $312 \cdot 75$ & $4 \cdot 27$ & $313 \cdot 33$ & 0.58 & NS \\
\hline \multicolumn{12}{|c|}{ Third time point (21st day) } \\
\hline $\mathrm{Hb}(\mathrm{g} / \mathrm{l})$ & $143 \cdot 50^{a, b}$ & $5 \cdot 00$ & $138 \cdot 00^{a, b}$ & $9 \cdot 90$ & $150 \cdot 75^{\mathrm{b}}$ & 4.57 & $131 \cdot 00^{a}$ & $6 \cdot 68$ & $147 \cdot 33^{b}$ & 3.79 & $<0.01$ \\
\hline Htc & $0.44^{\mathrm{a}, \mathrm{b}}$ & 0.02 & $0.43^{a, b}$ & 0.03 & $0.47^{a, b}$ & 0.02 & $0.43^{a}$ & 0.01 & $0.48^{\mathrm{b}}$ & 0.01 & $<0.01$ \\
\hline $\operatorname{Mcv}(\mathrm{fl})$ & $56 \cdot 88$ & 1.59 & $57 \cdot 05$ & $2 \cdot 62$ & $57 \cdot 75$ & $3 \cdot 21$ & $53 \cdot 88$ & 4.50 & $58 \cdot 83$ & 0.55 & NS \\
\hline Mch (pg) & $18 \cdot 33$ & 0.40 & $18 \cdot 15$ & 0.92 & $18 \cdot 30$ & 0.93 & $16 \cdot 55$ & 1.65 & $18 \cdot 20$ & 0.20 & NS \\
\hline $\operatorname{Mchc}(g / l)$ & $322 \cdot 50^{\mathrm{b}}$ & $3 \cdot 70$ & $322 \cdot 50^{a, b}$ & $3 \cdot 70$ & $317 \cdot 00^{a, b}$ & 5.89 & $306 \cdot 50^{\mathrm{a}}$ & $6 \cdot 45$ & $309 \cdot 00^{a, b}$ & $3 \cdot 61$ & $<0.01$ \\
\hline
\end{tabular}

DFE, diet deficient in folic acid and supplemented with Fe; DFOL, diet deficient in Fe and supplemented with folic acid; FEFOL, diet supplemented with Fe and folic acid; D, diet deficient in Fe and folic acid; C, control diet; Htc, haematocrit; Mcv, mean corpuscular volume; Mch, mean corpuscular Hb; Mchc, mean corpuscular Hb concentration.

${ }^{a, b}$ Mean values within a row with unlike superscript letters are significantly different $(P<0.05$; Scheffé's test).

* $P$ values show the significance levels for the differences between dietary groups within sample collection days.

highest in the $\mathrm{C}$ group $(P<0 \cdot 01)$. Mean corpuscular Hb concentration was significantly highest in the DFE group $(P<0 \cdot 01)$.

\section{Discussion}

The aim of the present study was to determine how FA and Fe deficiencies in rats, followed by dietary supplementation with these nutrients, affect the expression of folate and Fe transporters, and thereby FA and Fe status. As far as we know, this is the first time that the expression of these transporters has been analysed in a model that considers both deficiency of and supplementation with $\mathrm{Fe}$ and folate. Furthermore, the responses to the diets were observed at three time points, and the Fe and folate doses used reflected the amounts found in supplements. 
We observed lower transcript levels of Slc11a2 in the DFE than in the D animals at all three time points. This suggests that Fe supplementation during folate deficiency leads to decreased expression of Slc11a2. This is consistent with other studies in which the effect of Fe deficiency has been investigated in the duodenum, resulting in the increased expression of Slc11a2 ${ }^{(28)}$. Similar effects have also been observed in other tissues by others ${ }^{(29)}$. In our study, significantly lower expression levels of Slc11a2 were observed in the FEFOL group than in the D group at the second and third time points, which shows that the nutritional regimen triggered the response on the level of transcription. We did not observe any alterations between the groups in terms of protein levels after the supplementation period. This was most likely due to other transporters ${ }^{(30)}$ and regulatory mechanisms which we have not investigated, such as two motifs in the $5^{\prime}$ regulatory region ${ }^{(31)}$, ubiquitination and proteasome degradation mediated by proteins like Ndfip1 and Ndfip2 ${ }^{(32)}$.

We also determined whether the changes in gene expression were related to metabolic parameters. Analysis of Fe metabolism showed that, at the first time point, TIBC and unsaturated $\mathrm{Fe}$ binding capacity concentrations were highest in the D group, but we did not observe any differences in the Fe concentrations. At the second time point, no between-group differences were observed, which may suggest that the animals adapted through compensatory mechanisms to the deficiency. In turn, at the third time point, we again observed the highest concentrations of TIBC in the D group, which may suggest that a longer period of deficiency led to alterations in the metabolic profile. This result is in line with the results concerning Slc11a2-expression of this gene was highest in the D group. Also at the third time point, no differences were seen between the FEFOL and the DFE group on either the transcript or metabolic level. The lack of such differences in serum Fe concentrations may be a result of Fe homeostasis regulation by hepcidin or other mechanisms ${ }^{(33)}$.

The mechanisms by which the Slc46a1 gene is transcriptionally regulated are still not well understood. The special role of this transporter was established after the discovery that its dysfunction leads to hereditary folate malabsorption ${ }^{(34)}$. The close regulation of Slc46a1 activation during deficiency and repletion states is crucial for folate homeostasis. In the present study, after $21 \mathrm{~d}$ of supplementation, different expression levels of Slc46a1 mRNA expression were observed in the DFE and the FEFOL groups. This is in agreement with previous observations that a diet deficient in FA leads to increases in the transcription of transporter genes ${ }^{(35)}$. It has also been shown in a male mice model that folate deficiency causes a thirteen-fold increase of Slc46a1 mRNA levels in mice fed deficient $v$. replete diet for 8 weeks ${ }^{(35)}$. However, we did not see any differences between the FEFOL and D groups. Nevertheless, this lack of statistically significant between-group difference may be explained by the high standard deviations in the D group. Surprisingly, after $10 \mathrm{~d}$ of supplementation, the expression level of Slc11a2 was lower in the $\mathrm{D}$ than in the $\mathrm{C}$ group. This may suggest that other transporters, such as reduced folate transporter (SLC19A1), contributed to this effect, as other studies have shown ${ }^{(36)}$. An earlier in vivo study showed that FA deficiencies also lead to an increase in the level of Slc19a1 mRNA and $\operatorname{protein}^{(37)}$. Our study investigated only one FA transporter, and so we may not have observed the difference between the deficient and the $\mathrm{C}$ groups.

A study somewhat similar to ours has shown that oversupplementation with folate by a factor of 10 resulted in a decrease in levels of reduced folate transporter and Pcft protein, but no changes were observed on the mRNA level ${ }^{(38)}$. A previous cell culture study showed that oversupplementation of FA results in decreased mRNA levels not only of Slc46a1 but also of reduced folate transporter and folate receptor ${ }^{(39)}$. However, these differences were observed in an in vitro model, while we performed an in vivo investigation. A study using a laying hen model has shown jejunal Slc46a1 mRNA down-regulation by dietary 5-MTHF supplementation, but not by FA supplementation $^{(40)}$. Differentiation between models, treatment times, doses and nutritional regimen may have led to such inconsistent results.

Interestingly, when we analysed folate concentrations between groups at different time points, we observed that, at the second and third time points, folate concentrations were similar in the DFOL, FEFOL and $\mathrm{C}$ group. This suggests that FA supplementation, as well as simultaneous FA and Fe supplementation, gives the same metabolic results. In other studies, high doses of FA (ten times the normal requirements) resulted in increased FA serum levels ${ }^{(38)}$. In our study, the DFE and FEFOL diets were designed to be similar to the doses provided by common supplements. However, the amounts of FA and Fe used, as well as the time of administration, did not result in increased FA concentrations in serum. FA supplementation also affected other metabolic parameters; in particular, Hcy concentrations were significantly lower in the DFOL, FEFOL and $\mathrm{C}$ groups than in the DFE and D groups at all three time points, which is consistent with previous findings ${ }^{(41)}$.

At the third time point, differences were seen in $\mathrm{Hb}$, haematocrit and the mean corpuscular $\mathrm{Hb}$ concentration. Interestingly, the highest $\mathrm{Hb}$ concentrations were in the FEFOL group as well as in the $\mathrm{C}$ group, which indicates that only simultaneous supplementation with FA and Fe compensates for the decreased $\mathrm{Hb}$ concentrations caused by the earlier period of the diet deficient with these nutrients. Although Hb concentrations in the DFE and FEFOL groups were in line with the activation of Slc11a2 and Slc46a1 transcription, we surprisingly did not observe any differences between groups at the protein level. However, we observed that the lowest median protein levels were in the DFEFOL group (insignificant). In vitro and in vivo studies have shown that oversupplementation with FA results in decreased uptake of this nutrient by cells ${ }^{(38,39)}$. Our study did not find a beneficial effect of FA supplementation or of simultaneous FA and Fe supplementation on plasma FA concentrations. These metabolic results are consistent with the expression of Slc46a1 at the mRNA and protein levels, which did not differ between the DFOL, DFEFOL and C groups, except for the significant difference in Slc46a1 mRNA expression in the DFOL and C groups at the second time point. The significantly lower concentration of FA in the D and DFE groups also agrees with the Slc46a1 mRNA differences between the DFE and FEFOL groups at the third time point.

The strength of our study is that it simultaneously investigates the expression of genes related to folate and Fe metabolism on 
the transcriptional and translational levels but also considers the metabolic response to short-, medium- and long-term dietary regimens. One limitation of our study is that it analysed only a few Fe and FA transporters.

\section{Conclusions}

The results of the present investigation show that FA and Fe deficiency in the rat, with subsequent dietary supplementation with $6 \mathrm{mg}$ FA and $150 \mathrm{mg}$ Fe per kg of diet, may affect transcription of genes that encode folate and Fe transporters, but not protein abundance. FA supplementation led to decreased Hcy levels, but this result seems unrelated to Pcft. Simultaneous supplementation with FA and Fe resulted in significantly higher $\mathrm{Hb}$ concentration than did supplementation with these nutrients alone. This physiological effect was reflected by changes in gene transcription, but not in protein levels. Most likely, other transporters and factors are responsible for this effect. Further studies are needed to better understand the mechanisms involved.

\section{Acknowledgements}

This research was funded by the Polish National Science Centre, grant number 2015/17/B/NZ7/02952. The Polish National Science Center had no role in the design, analysis or writing of this article.

A. R. drafted the manuscript, carried out biochemical and molecular analyses and analysed the data; J. S. designed the study; P. K. performed protein analysis; A. C. designed the study, performed gene transcription analysis and analysed the data.

There are no conflicts of interest.

\section{Supplementary material}

For supplementary materials referred to in this article, please visit https://doi.org/10.1017/S0007114519002721

\section{References}

1. Christian P, Mullany LC, Hurley KM, et al. (2015) Nutrition and maternal, neonatal, and child health. Semin Perinatol 39, 361-372.

2. Greenberg JA, Bell SJ, Guan Y, et al. (2011) Folic acid supplementation and pregnancy: more than just neural tube defect prevention. Rev Obstet Gynecol 4, 52-9.

3. Obwegeser R, Hohlagschwandtner M \& Sinzinger H (1999) Homocysteine- a pathophysiological cornerstone in obstetrical and gynaecological disorders? Hum Reprod Update 5 , 64-72.

4. Koury MJ \& Ponka P (2004) New insights into erythropoiesis: the roles of folate, vitamin $\mathrm{B}_{12}$, and iron. Annu Rev Nutr $\mathbf{2 4}$, 105-131.

5. Micle O, Muresan M, Antal L, et al. (2012) The influence of homocysteine and oxidative stress on pregnancy outcome. J Med Life 5, 68-73.

6. Gaiday AN, Tussupkaliyev AB, Bermagambetova SK, et al. (2018) Effect of homocysteine on pregnancy: a systematic review. Chem Biol Interact 293, 70-76.

7. De Marco P, Calevo MG, Moroni A, et al. (2001) Polymorphisms in genes involved in folate metabolism as risk factors for NTDs. Eur J Pediatr Surg 11, S14-S17.
8. Nazki FH, Sameer AS \& Ganaie BA (2014) Folate: metabolism, genes, polymorphisms and the associated diseases. Gene $\mathbf{5 3 3}$, 11-20.

9. Panel E \& Nda A (2015) Scientific opinion on dietary reference values for folate. ESFA J 12, 1-59.

10. Patanwala I, King MJ, Barrett DA, et al. (2014) Folic acid handling by the human gut: implications for food fortification and supplementation. Am J Clin Nutr 100, 593-599.

11. Low MSY, Speedy J, Styles CE, et al. (2016) Daily iron supplementation for improving anaemia, iron status and health in menstruating women. Cochrane Database Syst Rev, issue 4, CD009747.

12. Allen LH (2000) Anemia and iron deficiency: effects on pregnancy outcome. Am J Clin Nutr 71, 1280S-1284S.

13. Haider BA, Olofin I, Wang M, et al. (2013) Anaemia, prenatal iron use, and risk of adverse pregnancy outcomes: systematic review and meta-analysis. BMJ 346, f3443.

14. Alwan N \& Hamamy H (2015) Maternal iron status in pregnancy and long-term health outcomes in the offspring.JPediatr Genet 4, 111-123.

15. Wessling-Resnick M (2017) Excess iron: considerations related to development and early growth. Am J Clin Nutr 106, 1600S-1605S.

16. Visentin M, Diop-Bove N, Zhao R, et al. (2014) The intestinal absorption of folates. Annu Rev Physiol 76, 251-274.

17. Zhao R, Diop-Bove N, Visentin M, et al. (2011) Mechanisms of membrane transport of folates into cells and across epithelia. Annu Rev Nutr 31, 177-201.

18. Inoue K, Nakai Y, Ueda S, et al. (2008) Functional characterization of PCFT/HCP1 as the molecular entity of the carriermediated intestinal folate transport system in the rat model. Am J Physiol Liver Physiol 294, G660-G668.

19. Laftah AH, Latunde-Dada GO, Fakih S, et al. (2009) Haem and folate transport by proton-coupled folate transporter/haem carrier protein 1 (SLC46A1). Br J Nutr 101, 1150.

20. Garrick MD (2011) Human iron transporters. Genes Nutr 6, 45-54.

21. Conrad ME \& Umbreit JN (2002) Pathways of iron absorption. Blood Cells Mol Dis 29, 336-355.

22. West A-R \& Oates P-S (2008) Mechanisms of heme iron absorption: current questions and controversies. World J Gastroenterol 14, 4101-4110.

23. Canonne-Hergaux F, Fleming MD, Levy JE, et al. (2000) The Nramp2/DMT1 iron transporter is induced in the duodenum of microcytic anemia mk mice but is not properly targeted to the intestinal brush border. Blood 96, 3964-3970.

24. Canonne-Hergaux F, Levy JE, Fleming MD, et al. (2001) Expression of the DMT1 (NRAMP2/DCT1) iron transporter in mice with genetic iron overload disorders. Blood 97, 1138-1140.

25. Said HM, Chatterjee N, Haq RU, et al. (2000) Adaptive regulation of intestinal folate uptake: effect of dietary folate deficiency. Am J Physiol Physiol 279, C1889-C1895.

26. Subramanian VS, Chatterjee N \& Said HM (2003) Folate uptake in the human intestine: promoter activity and effect of folate deficiency. J Cell Physiol 196, 403-408.

27. Thakur S, Rahat B, Hamid A, et al. (2015) Identification of regulatory mechanisms of intestinal folate transport in condition of folate deficiency. J Nutr Biochem 26, 1084-1094.

28. Trinder D, Oates PS, Thomas C, et al. (2000) Localisation of divalent metal transporter 1 (DMT1) to the microvillus membrane of rat duodenal enterocytes in iron deficiency, but to hepatocytes in iron overload. Gut 46, 270-276.

29. Siddappa AJM, Rao RB, Wobken JD, et al. (2003) Iron deficiency alters iron regulatory protein and iron transport protein expression in the perinatal rat brain. Pediatr Res 53, 800-807. 
30. Morgan EH \& Oates PS (2002) Mechanisms and regulation of intestinal iron absorption. Blood Cells Mol Dis 29, 384-399.

31. Lee PL, Gelbart T, West C, et al. (1998) The human Nramp2 gene: characterization of the gene structure, alternative splicing, promoter region and polymorphisms. Blood Cells $\mathrm{Mol}$ Dis 24, 199-215.

32. Foot NJ, Dalton HE, Shearwin-Whyatt LM, et al. (2008) Regulation of the divalent metal ion transporter DMT1 and iron homeostasis by a ubiquitin-dependent mechanism involving Ndfips and WWP2. Blood 112, 4268-4275.

33. Wallace DF (2016) The regulation of iron absorption and homeostasis. Clin Biochem Rev 37, 51-62.

34. Shin DS, Mahadeo K, Min SH, et al. (2011) Identification of novel mutations in the proton-coupled folate transporter (PCFT-SLC46A1) associated with hereditary folate malabsorption. Mol Genet Metab 103, 33-37.

35. Qiu A, Min SH, Jansen M, et al. (2007) Rodent intestinal folate transporters (SLC46A1): secondary structure, functional properties, and response to dietary folate restriction. Am J Physiol Physiol 293, C1669-C1678.
36. Liu M, Ge Y, Cabelof DC, et al. (2005) Structure and regulation of the murine reduced folate carrier gene. J Biol Chem $\mathbf{2 8 0}$, 5588-5597.

37. Wani NA, Thakur S \& Kaur J (2012) Mechanism of intestinal folate transport during folate deficiency in rodent model. Indian J Med Res 136, 758-65.

38. Dev S, Ahmad Wani N \& Kaur J (2011) Regulatory mechanisms of intestinal folate uptake in a rat model of folate oversupplementation. Br J Nutr 105, 827-835.

39. Ashokkumar B, Mohammed ZM, Vaziri ND, et al. (2007) Effect of folate oversupplementation on folate uptake by human intestinal and renal epithelial cells. Am J Clin Nutr 86, 159-166.

40. Jing M, Tactacan GB, Rodriguez-Lecompte JC, et al. (2010) Proton-coupled folate transporter (PCFT): molecular cloning, tissue expression patterns and the effects of dietary folate supplementation on mRNA expression in laying hens. Br Poult Sci 51, 635-638.

41. Cui S, Li W, Lv X, et al. (2017) Folic acid attenuates homocysteine and enhances antioxidative capacity in atherosclerotic rats. Appl Physiol Nutr Metab 42, 1015-1022. 